AperTO - Archivio Istituzionale Open Access dell'Università di Torino

\title{
Targeting Calcium Channels to Block Tumor Vascularization.
}

\section{This is the author's manuscript}

Original Citation:

Availability:

This version is available http://hdl.handle.net/2318/104370

since 2015-12-23T12:01:14Z

Terms of use:

Open Access

Anyone can freely access the full text of works made available as "Open Access". Works made available under a Creative Commons license can be used according to the terms and conditions of said license. Use of all other works requires consent of the right holder (author or publisher) if not exempted from copyright protection by the applicable law. 


\section{(6) \\ UNIVERSITÀ DEGLI STUDI DI TORINO}

This is an author version of the contribution published on:

Questa è la versione dell'autore dell'opera:

[inserire titolo della rivista, volume e fascicolo, anno, DOI]

ovvero [autore, volume, editore, anno, pagg.XXXX-XXXX]

The definitive version is available at:

La versione definitiva è disponibile alla URL:

[inserire URL sito editoriale] 


\section{HYDROGEN SULFIDE AS A REGULATOR OF GALGIUM GHANNELS}

Luca Munaron ${ }^{1,2,3}$, Daniele Avanzato ${ }^{1}$, Francesco Moccia ${ }^{4}$, Daniele Mancardi ${ }^{5}$

${ }^{1}$ Department of Life Sciences \& Systems Biology ${ }^{2}$ Center for Complex Systems in Molecular Biology and Medicine (SysBioM) ${ }^{3}$ Nanostructured Interfaces and Surfaces Centre of Excellence (NIS), University of Torino, Italy, ${ }^{4}$ Department of Biology and Biotechnologies "Lazzaro Spallanzani", University of Pavia, Italy, ${ }^{5}$ Dept. of Clinical and Biological Sciences, University of Torino, Orbassano (TO), Italy

Running title: $\mathrm{H}_{2} \mathrm{~S}$ and calcium channel regulation

Keywords: $\mathrm{H}_{2} \mathrm{~S}$, sulfhydration, calcium channels, regulation, cell signaling

*Correspondence to:

Luca Munaron, Ph.D.

Dept. Life Sciences \& Systems Biology

University of Torino

Via Accademia Albertina 13

10123 Torino

ITALY

luca.munaron@,unito.it 


\begin{abstract}
An increasing body of evidence suggests the involvement of hydrogen sulfide $\left(\mathrm{H}_{2} \mathrm{~S}\right)$ in different physiological and pathological processes. Similarly to the other gasotransmitters nitric oxide (NO) and carbon monoxide $(\mathrm{CO})$, this bioactive compound is rapidly diffusible through the biological membranes and acts in a paracrine fashion. Despite the large amount of biological actions observed in vitro and in vivo upon stimulation with $\mathrm{H}_{2} \mathrm{~S}$ donors, as well as by interfering with its synthesis, the molecular targets and mechanisms through which it exerts its intracellular effects are only partially known. A number of proteins are covalently modified by $\mathrm{H}_{2} \mathrm{~S}$ through sulfhydration of specific cysteine residues. However, only in few cases their identity has been discovered and the functional role of this post-translational modification needs to be investigated in more detail. Great attention has been devoted to potassium channels, particularly $\mathrm{K}_{\mathrm{ATP}}$, as they are considered key mediators of $\mathrm{H}_{2} \mathrm{~S}$-induced effects, and their sulfhydration has been clearly demonstrated. Recently, different authors reported the ability of $\mathrm{H}_{2} \mathrm{~S}$ to interfere with calcium homeostasis in neurons, cardiomyocytes and endothelial cells. Since calcium signaling is involved in all cell processes, these observations attracted increasing attention from basic biology and medicine. Although some effects of $\mathrm{H}_{2} \mathrm{~S}$ on calcium signals can be ascribed to $\mathrm{K}_{\mathrm{ATP}}$ modulation, there is growing consensus about the existence of other targets for the gasotransmitter. Some of them are $\mathrm{Ca}^{2+}$-permeable channels. In this review we discuss the state of the art in this specific field, providing an updated report of $\mathrm{H}_{2} \mathrm{~S}$ interaction with $\mathrm{Ca}^{2+}$ channels and its functional outcomes.
\end{abstract}




\section{Introduction}

Hydrogen sulfide $\left(\mathrm{H}_{2} \mathrm{~S}\right)$ is a colorless, flammable gas with a characteristic smell of rotten eggs that has long been regarded as a toxic environmental pollutant with minimal, if any, physiological significance [1]. It is, however, now evident that $\mathrm{H}_{2} \mathrm{~S}$ may be endogenously synthesized in mammalian tissues from L-cysteine by three pyridoxal-50-phosphate (PLP)-dependent enzymes, namely cystathionine $\beta$-synthase (CBS), cystathionine $\gamma$-lyase (CSE), and cysteine aminotransferase (CAT) [2]. The latter, in turn, acts in concert with the zinc-dependent enzyme, 3-mercaptopyruvate sulfurtransferase (3-MST), to release $\mathrm{H}_{2} \mathrm{~S}$ from L-cysteine and keto acids (e.g., $\boldsymbol{\alpha}$-ketoglutarate) $[1,3,4]$. The distribution of $\mathrm{H}_{2} \mathrm{~S}$-generating enzymes may be tissue specific, whereas CBS is highly expressed in the hippocampus and in the cerebellum within the central nervous system (CNS), and CSE is far more abundant in vascular smooth muscle cells (VSMCs) and endothelial cells (ECs) $[1,3,5]$. Nevertheless, recent studies have detected CSE in microglial cells, spinal cord and cerebellar granule neurons [6]. An additional source of $\mathrm{H}_{2} \mathrm{~S}$ is provided by bound sulfur, an intracellular reservoir of sulfur, as reported in rodent neurons and astrocytes in the presence of physiologic levels of endogenous reducing substances, i.e. glutathione and cysteine [1]. Interconversion of sulfur-containing amino acids and metabolites is carried out by cysteine CAT, cysteine dioxygenase (CDO), and cysteine lyase (CL) [1]. The assessment of the physiological concentration of free $\mathrm{H}_{2} \mathrm{~S}$ has engendered a remarkable controversy. It has long been thought that $\mathrm{H}_{2} \mathrm{~S}$ levels in biological tissues and plasma ranged from $50 \mu \mathrm{M}$ up to $160 \mu \mathrm{M}$ $[7,8]$. However, recent studies have disclosed that $\mathrm{H}_{2} \mathrm{~S}$ is rapidly catabolized such that 1) whole tissue concentrations of the free gasotransmitter fall within the low nanomolar range and 2) $\mathrm{H}_{2} \mathrm{~S}$ may be undetectable in peripheral blood $[1,9,10]$. In order to reconcile this evidence with the notion that $\mathrm{H}_{2} \mathrm{~S}$ impacts on cellular activities in vitro at concentrations that are orders of magnitude larger $(100 \mu \mathrm{M})$, it has been hypothesized that the equilibrium between $\mathrm{H}_{2} \mathrm{~S}$ production and consumption results in an intracellular microenvironment with enough $\mathrm{H}_{2} \mathrm{~S}$ to induce a local signalling cascade without affecting systemic levels of the gas $[9,11]$.

A number of signal transduction pathways may be recruited by $\mathrm{H}_{2} \mathrm{~S}$ to finely tune cardiovascular and CNS functions. For instance, $\mathrm{H}_{2} \mathrm{~S}$ relaxes VSMCs and contributes to the regulation of blood pressure by activating ATP-sensitive $\mathrm{K}^{+}$channels $\left(\mathrm{K}_{\mathrm{ATP}}\right)$; it promotes angiogenesis and vascular remodelling via 
phosphatidylinositol 3-kinase (PI3-K)/Akt/survivin axis in EGs and by augmenting the phosphorylation of extracellular signal-related kinase (ERK) and p38 in VSMCs; moreover, it downregulates a number of proinflammatory genes involved in the cardiac ischemic/reperfusion injury by preventing the nuclear translocation of the nuclear factor- $\kappa \mathrm{B}(\mathrm{NF}-\kappa \mathrm{B})$; it also stimulates long term synaptic potentiation by enhancing the activity of NMDA receptors upon the activation of the cAMP/protein kinase A cascade [1, 3, $5-8,11]$.

When considering the impact exerted by intracellular $\mathrm{Ca}^{2+}$ concentrations $\left(\mathrm{Ca}_{\mathrm{i}}\right)$ dynamics on cell physiology, it is not surprising that a growing number of studies are attempting to elucidate the involvement of $\mathrm{Ca}^{2+}$-permeable channels in $\mathrm{H}_{2} \mathrm{~S}$-related signalling. The present review aims at providing an updated and concise description of the interaction of $\mathrm{H}_{2} \mathrm{~S}$ with different types of plasmalemmal $\mathrm{Ca}^{2+}$ channels and the associated functional outcomes.

\section{S-sulfhydration is a regulatory mechanism for ion channels}

Gasotransmitters, such as nitric oxide $(\mathrm{NO})$, carbon monoxide $(\mathrm{CO})$ and $\mathrm{H}_{2} \mathrm{~S}$, selectively interact with different types of ion channels [1, 3, 5, 12-16]. Carbon monoxide modulates (positively or negatively) largeconductance calcium-activated $\mathrm{K}^{+}\left(\mathrm{BK}_{\mathrm{Ca}}\right)$, voltage-activated $\mathrm{K}^{+}\left(\mathrm{K}_{\mathrm{V} 2.1}\right)$ and $\mathrm{L}$-type $\mathrm{Ca}^{2+}$ channels, ligandgated P2X2 and P2X4 receptors, tandem $\mathrm{P}$ domain $\mathrm{K}^{+}$channels (TREK1) and the epithelial $\mathrm{Na}^{+}$channel (ENaC). The detailed mechanisms underlying these effects are not clear. Carbon monoxide activates soluble guanylyl cyclase (sGC), leading to the release of cGMP, but it can also directly modify target proteins such as $\mathrm{K}_{\mathrm{Ca}} \alpha$-subunit through interaction with aspartate and histidine residues [17, 18]. Nitric oxide covalently modifies free sulfhydryl $(-\mathrm{SH})$ of cysteine residues via protein S-nitrosylation. Among ion channels, $\mathrm{K}_{\mathrm{Ca}}$, ultrarapid delayed rectifier $\mathrm{K}^{+}$current $\left(\mathrm{K}_{\mathrm{V} 1.5}\right), \mathrm{K}_{\mathrm{ATP}}$, delayed rectifier $\mathrm{K}^{+}$, L-type $\mathrm{Ca}^{2+}$ channels, and Transient Receptor Potential (TRP) channels are (positively or negatively) modulated by S-nitrosylation [19, 20].

$\mathrm{H}_{2} \mathrm{~S}$ donors can also modify cysteine residues of different proteins through S-sulfhydration $[1,5]$. The - SH from sulfhydryl donor is transferred to free cysteine sulfhydryl and forms covalent persulfide (- 
SSH). Sulfhydration can be detected by a modified biotin-switch assay used for nitrosylation as well as by mass spectrometry [5]. A number of $\mathrm{H}_{2} \mathrm{~S}$-releasing drugs have been utilized to mimic the endogenous effects of $\mathrm{H}_{2} \mathrm{~S}$ under experimental conditions [1, 2]. The most popular $\mathrm{H}_{2} \mathrm{~S}$ donor is sodium hydrosulfide (NaHS), which presents a fast releasing rate in aqueous solution and liberates one third of $\mathrm{H}_{2} \mathrm{~S}$ compared to the concentration of the salt [8].

Several proteins are sulfhydrated including actin, tubulin, and glyceraldehyde-3-phosphate dehydrogenase (GAPDH), strengthening the idea that this signaling pathways is biologically relevant [5]. Accordingly, a recent report showed that $\mathrm{H}_{2} \mathrm{~S}$-linked sulfhydration of NF-kB p65 subunit at cysteine-38 mediates its anti-apoptotic action in macrophages and liver cells [21].

In the vascular tissue, hydrogen sulfide is considered an endothelium-derived hyperpolarizing factor (EDHF) that is released by EGs and affects $\mathrm{K}^{+}$channels including intermediate calcium-dependent $\mathrm{K}^{+}$ ( $\left.\mathrm{IK}_{\mathrm{Ca}}\right)$, small calcium-dependent $\mathrm{K}^{+}\left(\mathrm{SK}_{\mathrm{Ca}}\right)$ and $\mathrm{K}_{\mathrm{ATP}}$ in VSMCs [13]. In VSMCs of rat mesenteric arteries $\mathrm{H}_{2} \mathrm{~S}$ sulfhydrates Kir 6.1 subunit of $\mathrm{K}_{\mathrm{ATP}}$ in cysteine-43, both constitutively and during cholinergic simulation [13]. Previous observations by Jiang and co-workers showed that $\mathrm{H}_{2} \mathrm{~S}$ directly interacts with cysteine-6 and cysteine-26 residues of the extracellular $\mathrm{NH}_{2}$ terminal of rat vascular sulfonylurea receptor (rvSUR1) subunit of rvKir6.1 $\mathrm{K}_{\mathrm{ATP}}$ channels [13, 22]. This study, however, did not assess whether $\mathrm{H}_{2} \mathrm{~S}$ formed persulfides with the exposed free cysteine residues or disassembled the related disulfide bonds [12].

In addition to $\mathrm{K}^{+}$channels, also voltage-dependent $\mathrm{Na}^{+}$channels $\left(\mathrm{Na}_{\mathrm{v}}\right)$ can be regulated by $\mathrm{H}_{2} \mathrm{~S}$. Native (from jejunum smooth muscle) and recombinant $\left(\mathrm{Na}_{\mathrm{v}} 1.5\right) \mathrm{Na}_{\mathrm{v}}$ currents are increased by NaHS with an associated positive shift in steady-state activation and inactivation kinetics. Although the high (mM) concentrations of NaHS employed in this study suggest caution about their physiological significance, this effect could extend beyond the jejunum, since Nav1.5 is expressed in other tissues. In the heart, it gives rise to the upstroke of the cardiac action potential [23], whilst in Human Umbilical Vascular Endothelial Cells (HUVEGs) $\mathrm{Na}_{\mathrm{v}}$ regulates angiogenic calcium signals [24].

\section{S-sulfhydration of calcium channels}




\section{Calcium VOCs}

Voltage-activated $\mathrm{Ca}^{2+}$ channels $\left(\mathrm{Ca}_{\mathrm{v}}\right)$ are expressed at high density in excitable cells, but are also detectable in some non-excitable tissues. They are typically classified as high voltage-activated (HVA) and low voltageactivated (LVA) channels, based on their electrophysiological features. HVA channels include L-, N-, P/Q-, and R-type, while LVA channels conduct T-type calcium currents [25]. $\mathrm{Ca}_{\mathrm{v}}$ are mostly abundant in neurons, cardiac conduction system and smooth muscles.

$\mathrm{H}_{2} \mathrm{~S}$ modulates cardiovascular homeostasis and exerts cardioprotective effects in different models of in vitro, ex vivo and in vivo ischemia/reperfusion [11, 16, 26-33]. Indeed, whole patch clamp experiments in rat cardiomyocytes revealed that NaHS negatively modulates L-type $\mathrm{Ca}^{2+}$ channels composed by the Cav1.2 subunits [12, 30, 34]. More specifically, NaHS (up to $1 \mathrm{mM}$ ) causes a dose-dependent reduction in the $\mathrm{Ca}^{2+}$ current peak. This effect is only partial: the current density diminishes by $50 \%$ at $1 \mathrm{mM}$ NaHS [34]. The mechanism could involve a direct modification of Caa free sulfhydryl groups [34].

The $\mathrm{H}_{2} \mathrm{~S}$ donor also affects the recovery from depolarization-induced inactivation, without altering the steady state activation and inactivation curves. Accordingly, the shortening of single cardiomyocytes and contraction of isolated rat papillary muscles are depressed. Electric field-induced $\mathrm{Ca}_{\mathrm{i}}$ transients in single cardiomyocytes are also reduced by 100 $\mu \mathrm{M}$ NaHS $[12,30]$. Consistently, $\mathrm{H}_{2} \mathrm{~S}$ exerts a negative inotropic effect in isolated perfused rat and papillary muscles when NaHS is administrated at concentrations ranging from $1 \mu \mathrm{M}$ up to $1 \mathrm{mM}[35,36]$. More recently, it has been reported its negative chronotropic action in human atrial fibers by blocking L-type $\mathrm{Ca}^{2+}$ channels and an enhancement in the repolarization phase by opening $\mathrm{K}_{\mathrm{ATP}}$ channels (50-200 $\mu \mathrm{M}$ NaHS) [37]. Interestingly, according to a recent study, $\mathrm{H}_{2} \mathrm{~S}$ can reverse the negative inotropic effect induced by $\mathrm{NO}$ by causing an increase in the peak amplitude of the electrically stimulated $\mathrm{Ca}_{\mathrm{i}}$ transients [33]. These apparently discrepant data may be reconciled when considering that, under such conditions, the modulation of the $\mathrm{Ca}_{\mathrm{i}}$ toolkit responsible for the positive inotropic effect is not accomplished by $\mathrm{H}_{2} \mathrm{~S}$, but by a new thiol-sensitive endogenous modulator deriving from the interaction between the two gasotransmitters [33]. Interestingly, in this report, $\mathrm{H}_{2} \mathrm{~S}$ was provided by $\mathrm{NaHS}$ at low micromolar doses $(10 \mu \mathrm{M})$.

The negative effect of $\mathrm{H}_{2} \mathrm{~S}$ on $\mathrm{Ca}^{2+}$ influx is not limited to the cardiovascular system. Similarly to rat cardiomyocytes, $100 \mu \mathrm{M}$ NaHS suppresses voltage-gated $\mathrm{Ca}^{2+}$ currents in INS-1E cells (rat insulinoma cell line) and native pancreatic beta-cells: these currents are sensitive to both nifedipine and Bay K-8664, a pharmacological profile consistent with L-type $\mathrm{Ca}^{2+}$ channels [12]. 
On the other hand the effects of NaHS on neurons, that can express both Cav1.2 and Cav1.3 subtypes, seem to be opposite [38]. In cultured rat cerebellar granule neurons (CGN), NaHS (50-300 $\mu \mathrm{M})$ induces cell death as well as $\mathrm{Ca}_{\mathrm{i}}$ signals sensitive to nifedipine and nimodipine, L-type $\mathrm{Ca}^{2+}$ channel blockers [12]. However, no electrophysiological recordings were conducted and a direct activation of L-type $\mathrm{Ca}^{2+}$ channels by NaHS remains to be demonstrated yet. Moreover, there is no evidence about the molecular nature (i.e. Gav1.2 or Cav1.3) of L-type channels in these cells. Taken together, these evidences suggest that L-type $\mathrm{Ca}^{2+}$ channels are inhibited by $\mathrm{H}_{2} \mathrm{~S}$ in the myocardium, whereas they are enhanced by the same $\mathrm{H}_{2} \mathrm{~S}$ doses in the CNS. Future investigations will unveil whether this feature depends on the different molecular make-up of L-type channels, i.e. Cav1.2 in ventricular cardiomyocytes vs. Cav1.3 in the cerebellum, or on their associated subunits. Alternatively, an intermediate sensor coupled to the channel complex, whose nature varies between the heart and the CNS, might mediate the regulation of L-type $\mathrm{Ca}^{2+}$ channels by $\mathrm{H}_{2} \mathrm{~S}$.

NaHS increases $\mathrm{Ca}_{i}$ also in astrocytes, hippocampal slices and microglia, through currents sensitive to $\mathrm{Ca}^{2+}$ channel inhibitors $\left(\mathrm{La}^{3+}\right.$ and $\left.\mathrm{Gd}^{3+}\right)$ and in a concentration range $(100-500 \mu \mathrm{M})$ similar to that affecting VOCs $[12,39]$. It appears that $\mathrm{H}_{2} \mathrm{~S}$-triggered $\mathrm{Ca}_{\mathrm{i}}$ waves are due to influx through $\mathrm{Ca}^{2+}$ channels on plasma membrane and, to a lesser extent, to the release from intracellular $\mathrm{Ca}^{2+}$ stores $[12,39]$. In contrast, a recent report showed that NaHS-induced $\mathrm{Ca}_{\mathrm{i}}$ increase in isolated rat colonic crypts was not dependent on extracellular $\mathrm{Ca}^{2+}$, but was affected by blockade of either ryanodine receptors (RyRs) or sarco/endoplasmic reticulum Ca2+-ATPase (SERCA) [40].

T-type $\mathrm{Ca}^{2+}$ channels are encoded by the three members of the Cav3 subfamily and display different biophysical and pharmacological features as compared to L-type $\mathrm{Ca}^{2+}$ channels: activation at lower membrane potentials, faster inactivation, slower deactivation, smaller permeability to $\mathrm{Ba}^{2+}$, insensitivity to dihydropyridines and block by $\mathrm{ZnCl}_{2}$ [41]. T-type $\mathrm{Ca}^{2+}$ currents are involved in a great number of physiological processes, such as neuronal firing, hormone secretion, smooth muscle contraction, myoblast fusion, and fertilization [41]. Moreover, they play critical roles in mediating either somatic or visceral nociceptive information. Similarly to capsaicin, NaHS, injected intracolonically at 0.5-5 nM per mouse, triggers visceral nociceptive responses in vivo, which are completely abolished by mibefradil, an unspecific Ttype channel blocker, and insensitive to verapamil and to the $\mathrm{K}_{\mathrm{ATP}}$ channel blocker glibenclamide [12]. 
Therefore, $\mathrm{H}_{2} \mathrm{~S}$ may function as a novel nociceptive messenger through the activation of peripheral T-type $\mathrm{Ca}^{2+}$ channels, particularly during inflammatory processes. However, since mibefradil is not selective for Ttype channels, this conclusion should be confirmed by future investigations [42].

Furthermore, both intraplantar (1 nM/paw) and intratechal (0.01-0.1 nM/animal) administration of NaHS caused a prompt hyperalgesia in rats, an effect that was abolished by mibefradil, $\mathrm{ZnCl}_{2}$, or antisense oligodeoxynucleotides (ODNs) selectively targeting rat Cav3.2 [43-45]. The finding that DLpropargylglycine (PPG) and $\beta$-cyanoalanine, two CSE inhibitors, abolish the L-cysteine-induced hyperalgesia and attenuate the lipopolysaccharid-induced hyperalgesia, an effect reversed by NaHS, supports these observations [43, 44]. Moreover, mibefradil suppressed the phosphorylation of ERK induced by the infusion of NaHS, a pronociceptive stimulus in the pancreatic duct, albeit at higher concentrations than those reported above (500 nM/rat) [46]. Finally, the neuropathic allodynia/hyperalgesia induced in rats by damaging the right L5 spinal nerve [47] or by systemic injection of paclitaxel [48], an anticancer drug, was strongly attenuated by either mibefradil or CSE inhibitors, or by antisense ODNs against rat Cav3.2. In addition, Cav3.2 was significantly up-regulated in the ipsilateral L4, L5, and L6 dorsal root ganglia of rats subjected to spinal nerve injury, but not treated with paclitaxel [48]. A redox modulation of Cav3.2 has been proposed, since NaHS increases the amplitude of T-type $\mathrm{Ca}^{2+}$ currents in a neuroblastoma cell line without affecting their kinetics. This effect was reversed by the oxidizing agent, 5,5'dithio-bis(2-nitrobenzoic acid) (DTNB), and mimicked by the reducing compound, dithiothreitol (DTT) [44]. It should be pointed out that the elevation in the density of T-type $\mathrm{Ca}^{2+}$ currents was observed at 0.5-1.5 mM NaHS, i.e. at a concentration considerably higher than that reported to affect L-type VOCs (see above). The enhancement of T-type $\mathrm{Ca}^{2+}$ current by the exogenous application of $\mathrm{H}_{2} \mathrm{~S}$, in turn, induces neuronal differentiation, as revealed by neurite outgrowth and functional expression of high voltage-activated $\mathrm{Ca}^{2+}$ currents, including L, P/Q-, and N-type channels [49]. Once again, these effects arose when NaHS was administrated at 1.5-13.5 mM. Interestingly, earlier reports demonstrated that L-cysteine selectively potentiates recombinant Cav3.2dependent, but not Gav3.1- and Cav3.3-, currents [50]. A mechanistic link between $\mathrm{H}_{2} \mathrm{~S}$ and the onset of the $\mathrm{Ca}_{\mathrm{i}}$ waves might be provided by the protein-kinase A (PKA)\cAMP pathway. Accordingly, H-89, a rather selective PKA blocker, hinders NaHS-evoked $\mathrm{Ca}_{\mathrm{i}}$ signals in both neurons and microglial cells [51, 52]. Moreover, PKA-dependent phosphorylation may increase the $\mathrm{Ca}^{2+}$ permeability of T-type channels, NMDA 
receptors, and RyRs (see Discussion in [51]).

\section{Transient receptor potential (TRP) channels}

TRP channels can be activated by a variety of stimuli, including $\mathrm{Ca}^{2+}$ stores depletion, shear stress, pulsatile stretch, receptor activation, changes in temperature and osmolarity, and intracellular second messengers [53]. Their versatility enables TRP channels to control cellular functions as diverse as proliferation, differentiation, gene expression, migration, cytoskeleton remodelling, apoptosis, transmitter release, and NO synthesis [54]. It has now been widely established that TRP channels may also be modulated by covalent posttranscriptional modifications. For instance, TRP channels are S-nitrosylated at cysteine-553 and cysteine-558, located next to the channel pore [19]. Furthermore, TRPA1 is sensitive to thiol-reactive electrophiles that bind to cysteine residues located in the $\mathrm{NH}_{2}$-terminus of the channel [55]. In addition, $\mathrm{H}_{2} \mathrm{~S}$ and its donors trigger TRPV1 opening that mediates chloride secretion in colon, gut motility, acute pancreatitis, airway constriction, and bladder contractility [12, 56-61]. Serosal application of NaHS (0.2-2.5 $\mathrm{mM}$ ) and L-cysteine stimulates luminal chloride secretion by guinea pig, rat and human colon [12, 40, 58]. This effect is blocked by tetrodotoxin (TTX), by desensitization of afferent nerves with capsaicin, or by TRPV1 antagonist capsazepine [58]. This suggests that $\mathrm{H}_{2} \mathrm{~S}$-stimulated mucosal secretion is dependent on TTX-sensitive $\mathrm{Na}^{+}$channels and/or TRPV1 channels of sensory nerve endings. Recent works showed that TRPV1-mediated $\mathrm{Ca}^{2+}$ entry enhances substance $\mathrm{P}$ release from afferent nerves, which, in turn, excite cholinergic secremotor neurons by activating neurokin-1, -2, or -3 (NK1-3) receptors [62, 63]. It should, however, be noted that NaHS-induced chloride secretion in rat distal colon is inhibited by glibenclamide and tetrapentylammonium, suggesting the involvement of different types of $\mathrm{K}^{+}$channels, including $\mathrm{K}_{\mathrm{ATP}}$ and $\mathrm{K}_{\mathrm{Ca}}$.

$\mathrm{H}_{2} \mathrm{~S}$ donors mimick the effect of capsaicin, leading to the release of calcitonin gene-related peptide (CGRP) and substance $\mathrm{P}$ from the sensory nerves in the guinea pig airways $[12,57]$. More specifically, $50 \mathrm{mM}$ NaHS causes in vivo bronchoconstriction and microvascular leakage in a capsazepine-sensitive manner, contributing to the irritant action of $\mathrm{H}_{2} \mathrm{~S}$ on the respiratory system. NaHS triggers a dose-dependent contraction of isolated bronchial and tracheal rings in vitro $\left(\mathrm{IC}_{50}\right.$ about $\left.1.3 \mathrm{mM}\right)$ : this effect is abolished by sensory nerve desensitization with high concentration of capsaicin, by TRPV1 antagonists (ruthenium red, capsazepine and 
SB366791), as well as by a mixture of NK1 (substance P receptor) and NK2 receptor (CGRP receptor) antagonists [12]. Interestingly, intraperitoneal injection of NaHS $(1-10 \mathrm{mg} / \mathrm{kg})$ to healthy mice induced substantial lung inflammatory reactions. These effects were abolished by a specific NK1 receptor antagonist, but not by NK2 receptor antagonists. In addition, the inflammatory effect of $\mathrm{H}_{2} \mathrm{~S}$ was abolished by capsazepine and was not observed in mice lacking substance $\mathrm{P}$ and neurokinin-A due to the knockout of their common precursor gene, preprotachykinin-A [57].

TRPV1 mediates neurogenic inflammation in pancreatitis, and the effect is blocked by pretreatment with TRPV1 antagonist capsazepine or NK1 receptor antagonist CP96, 345 [12, 59]. Notably, an increase in plasma $\mathrm{H}_{2} \mathrm{~S}$ levels is induced in caerulein-induced pancreatitis and the therapeutic administration of PAG attenuates the pancreatic inflammation and partially reverses the associated lung injury [56]. Similarly, TRPV1 underpinned the $\mathrm{H}_{2} \mathrm{~S}$-dependent neurogenic inflammation in polymicrobial sepsis by increasing substance $\mathrm{P}$ production and activating the ERK/NF-kB pathway $[64,65]$. In these experiments, NaHS was orally administrated at $10 \mathrm{mg} / \mathrm{kg}$. Conversely, $\mathrm{H}_{2} \mathrm{~S}$ may prevent ethanol-induced gastric lesions in mice by stimulating TRPV1 channels on the capsaicin-sensitive primary afferent neurons that innervate the gastric mucosa [66]. Indeed, pretreating the animals with capsazepine reversed the gastroprotective action of either L-cysteine or NaHS (75-300 $\mu \mathrm{M} / \mathrm{Kg})[66]$.

In contrast to its vasorelaxant effect, NaHS $(30 \mu \mathrm{M}-3 \mathrm{mM})$ triggers contraction of the detrusor muscle in the rat urinary bladder $[60,61]$. As in previously described cases, a direct effect of $\mathrm{H}_{2} \mathrm{~S}$ on the muscle seems unlikely: it is abolished by the combination of NK1 and NK2 receptor-selective antagonists as well as by high-capsaicin pretreatment, which could desensitize capsaicin-sensitive primary afferent neurons. The response to NaHS is not dependent on $\mathrm{Na}_{\mathrm{v}}$ channels since it is mostly resistant to TTX. $\mathrm{H}_{2} \mathrm{~S}$ could stimulate capsaicin-sensitive primary afferent nerve terminals and the following release of tachykinins, leading to the contractile response. Furthermore, ruthenium red (RR), an unspecific blocker of TRPV1 channels, but not TRPV1 selective antagonist capsazepine, reduces the $\mathrm{H}_{2} \mathrm{~S}$-induced contractile response. This opens the possibility that other RR-sensitive channels, such as TRPV1-6 and TRPA1, could be involved. TRPA1 is expressed on capsaicin-sensitive primary sensory neurons where it mediates pain, protective reflexes, and local release of peripheral neurotransmitters [67-69]. This channel is involved in noxious cold- and mechano- 
sensations and its activators (allyl isothiocyanate, cinnamaldehyde, allicin, and acrolein) interact with cysteine residues of the protein. In female Sprague-Dawley rat bladder, TRPAl is located in unmyelinated sensory nerve fibres where it colocalizes with TRPV1 channels [70]. Interestingly, TRPA1-expressing nerve fibres are also detected around blood vessels in the suburothelial region and muscular layer of the bladder [69, 71$]$. TRPAl stimulation enhances detrusor activity. After disruption of the urothelial barrier with protamine sulfate, $1 \mathrm{mM}$ NaHS increases maximal bladder pressure, reduces voided and infused volumes, and voiding interval $[12,70]$. Recent work extended these observations to the human lower urinary tract, where TRPA1 channels are expressed in the terminal afferents of the urothelium and in basal urothelial cells [72]. After precontraction with phenylephrine, both TRPAl agonists and NaHS are able to trigger relaxation of urethral strip preparations [72]. NaHS ( $\mathrm{IC}_{50} \approx 1.2 \mathrm{mM}$ ) evokes $\mathrm{Ca}_{\mathrm{i}}$ increase in CHO cells expressing mouse or human TRPA1 [70]. Accordingly, in rat Dorsal Root Ganglia (DRG) neurons, NaHS-induced Cai signals were abolished by removal of extracellular $\mathrm{Ca}^{2+}$ and by selective blockade of TRPAl channels with HC030031 [73]. Similar to the finding obtained on urethral strip preparations, the $\mathrm{IC}_{50}$ of the $\mathrm{Ca}_{\mathrm{i}}$ response to NaHS in DRG neurons was about 1.4 mM. Furthermore, NaHS evoked an HC-030031-sensitive inward current in rat DRG neurons clamped at a holding potential of $-80 \mathrm{mV}$. The current-to-voltage relationship of NaHS-induced current reversed at $0 \mathrm{mV}$ and showed a slight outward rectification at positive potentials: both features are consistent with the biophysical properties of TRPAl channels [73, 74]. Notably, NaHSinduced inward current was prevented by the reducing agent of disulfide bonds DTT, suggesting that $\mathrm{H}_{2} \mathrm{~S}$ carries out a covalent modifications of the cysteine residues located at the NH2-terminus of TRPA1 [73].

TRP channels may mediate the proangiogenic calcium influx triggered by $\mathrm{H}_{2} \mathrm{~S}$ in endothelial cells (EGs) [75-78]. In a recent paper, we investigated the effects of $\mathrm{H}_{2} \mathrm{~S}$ on microvascular ECs obtained from human breast carcinoma (B-TECs) [79]. $\mathrm{Ca}^{2+}$ imaging and patch-clamp experiments revealed that acute perfusion with NaHS activates $\mathrm{Ca}_{\mathrm{i}}$ increases, as well as $\mathrm{K}^{+}$and non-selective cationic currents. Stimulation with NaHS in the same concentration range $(1 \mathrm{nM}-200 \mu \mathrm{M})$ evoked $\mathrm{Ca}_{\mathrm{i}}$ signals also in 'normal' human microvascular ECs (HMVECs), but the amplitude was significantly lower. Conversely, doses lower than 10 $\mu \mathrm{M}$ NaHS did not evoke any detectable elevation in $\mathrm{Ca}_{i}$ in the excised endothelium of rat aorta [79]. Moreover, NaHS failed to promote either migration or proliferation on HMVECs, while B-TEC migration was enhanced at low-micromolar NaHS concentrations $(1-10 \mu \mathrm{M})$. Remarkably, pretreatment with the 
CSE-inhibitor PAG drastically reduced migration and $\mathrm{Ca}_{\mathrm{i}}$ signals induced by Vascular Endothelial Growth Factor (VEGF) in B-TECs. These data suggest that $\mathrm{H}_{2} \mathrm{~S}$ plays a role in proangiogenic signaling of tumorderived but not normal human ECs. Furthermore, its ability to interfere with B-TEG responsiveness to VEGF suggests that it could be an interesting target for antiangiogenic strategies in tumor treatment.

Although the identity of proangiogenic calcium channels regulated by $\mathrm{H}_{2} \mathrm{~S}$ in endothelial cells is still unknown, good candidates could be calcium-permeable channels involved in VEGF-dependent signaling. Different reports point to the ability of VEGF to activate TRPG1, TRPG3 and TRPG6 channels in human EG lines [80-86]. In addition, Orail and Stim1, components of the so-called CRAC channels, seem to contribute to VEGF-mediated $\mathrm{Ca}_{i}$ signaling in EGs [87-90]. The pattern of endothelial VEGF-activated channels could actually vary among different tissues, especially between small capillaries and large vessels. Remarkably, tumor-derived ECs express several members of TRP channels [91]. TRPV4 is overexpressed and functional in B-TECs, where it mediates arachidonic acid-dependent calcium entry and enhances migration [92]. Future investigations will unveil the potential role of this protein (and/or other TRP-related or unrelated channels) as a molecular target for the $\mathrm{H}_{2} \mathrm{~S}$-induced $\mathrm{Ca}^{2+}$ entry and its vascular effects.

\section{Conclusion and perspectives}

The investigation of cellular and molecular mechanisms underlying physiological and pathological roles of hydrogen sulfide is living an exciting phase that recalls the history of nitric oxide, another gasotransmitter of established and widespread biological relevance. However, despite the growing number of reports, the state of the art is still far from being exhaustive. In particular, the relationship between calcium- and $\mathrm{H}_{2} \mathrm{~S}$-dependent cell signaling has been clearly demonstrated in many cell types, including neurons, cardiomyocytes, endothelial cells, and is associated to relevant biological processes such as cardiac contraction, angiogenesis, inflammation and sensory transduction. As noted above, the most striking feature of this relationship is $\mathrm{H}_{2} \mathrm{~S}$ ability of either inhibiting or activating $\mathrm{Ca}^{2+}$ entry depending on the molecular nature of the $\mathrm{Ca}^{2+}$ entry pathway. Future investigation will have to address the following issues: 1) does $\mathrm{H}_{2} \mathrm{~S}$ modulate Cav1.3-dependent L-type $\mathrm{Ca}^{2+}$ channels? 2) Are Cav1.2, Cav1.3, Cav3.2 directly S-sulfydrated and, if so, does this covalent modification differently modulate Cav1.2 (inhibited) vs. Cav1.3 and Cav3.2 (activated) gating? 3) Is there any role for Cav-associated subunits in the modulation of voltage-gated $\mathrm{Ca}^{2+}$ influx by $\mathrm{H}_{2} \mathrm{~S}$ ? 4) Do TRPV1 and TRPA1 proteins undergo any direct covalent modification by $\mathrm{H}_{2} \mathrm{~S}$ or do they sense its levels via an intracellular sensor? 
It should be, finally, pointed out that the concentration of NaHS required to modulate/activate $\mathrm{Ca}^{2+}$ permeable channels is extremely variable. For instance, low- to mid-micromolar doses of NaHS regulate L-type VOCs, whereas T-type and TRPAl channels are stimulated by low millimolar doses of the donor. Such variability is more evident in vascular endothelium, where the threshold for the onset of the $\mathrm{Ca}_{\mathrm{i}}$ signal may vary from the low nanomolar range observed in B-TEGs and HMVEGs to the low micromolar range reported in RAECs. When considering that approximately one third of the salt concentration is released in form of $\mathrm{H}_{2} \mathrm{~S}$ in acqueous solution, it turns out that the effective concentration of $\mathrm{H}_{2} \mathrm{~S}$ may vary from $0.1 \mathrm{nM}$ up to around $400 \mu \mathrm{M}$ depending on the target channel. As mentioned above, a number of studies have been devoted to ascertain the concentration of endogenous $\mathrm{H}_{2} \mathrm{~S}$ in biological tissues. A recent paper proposed the existence of at least three discrete $\mathrm{H}_{2} \mathrm{~S}$ pools in various biological specimens: a free $\mathrm{H}_{2} \mathrm{~S}$ reservoir, which is in the low nanomolar range, an acid-labile and a bound sulfane- $\mathrm{H}_{2} \mathrm{~S}$ pools, which are in the low micromolar range. This finding introduces the notion of a reversible sulfide sink into and from which $\mathrm{H}_{2} \mathrm{~S}$ can be deposited or liberated to exert biologic functions [93]. The possibility that $\mathrm{H}_{2} \mathrm{~S}$ may reach intracellular levels high enough to activate local signaling pathways should also be taken in account. Nevertheless, the $\mathrm{H}_{2} \mathrm{~S}$ levels necessary to induce detectable changes in the activity of either T-type VOCs or TRPAl channels have never been measured, a feature that should be addressed by future investigations.

Although this review mainly focused on L- , T-type $\mathrm{Ca}^{2+}$ channels and TRP channels, it is worth of noting that preliminary data hint at additional $\mathrm{Ca}^{2+}$-permeable channels as novel targets of $\mathrm{H}_{2} \mathrm{~S}$. For instance, $\mathrm{H}_{2} \mathrm{~S}$ has been shown to regulate SOCE in both human EGs enzymatically dissociated from saphenous vein and rat aortic endothelium [94, 95]. Furthermore, $\mathrm{H}_{2} \mathrm{~S}$ may affect intracellular $\mathrm{Ca}^{2+}$ mobilization by either inhibiting Ins $\mathrm{P}_{3} \mathrm{Rs}$ or exciting RyrRs [40, 94]. These findings gain particular relevance when considering that Orail, the plasmalemmal pore-forming subunit of SOCE, Ins $\mathrm{P}_{3} \mathrm{Rs}$ and $\mathrm{RyRs}$ are all prone to covalent modifications, such as phosphorylations and nytrosilations. Consistently, future studies will be needed to elucidate the possible co-regulations of ion channels by $\mathrm{H}_{2} \mathrm{~S}$ and $\mathrm{NO}$ : similarly to other proteins, some calcium channels contain cysteine residues potentially target for both the gaseous mediators through nytrosilation and sulfhydration.

The interplay between $\mathrm{H}_{2} \mathrm{~S}$ and calcium signaling is made even more intricate by the fact that CSE activity can be $\mathrm{Ca}^{2+}$-calmodulin-dependent, as shown in bovine aortic endothelial cells (BAEGs) [96]. The possibility that $\mathrm{H}_{2} \mathrm{~S}$ undergoes an auto-regolatory control by either activating (via Cav3.2, TRPA1 or TRPV1) or inhibiting (via Cav1.2) $\mathrm{Ca}^{2+}$ entry will deserve future investigations. This feature would add another piece to the growing list of analogies between $\mathrm{NO}$ and $\mathrm{H}_{2} \mathrm{~S}$, 
whereas $\mathrm{NO}$, which is produced by the $\mathrm{Ca}^{2+} / \mathrm{CaM}$-dependent endothelial $\mathrm{NO}$ synthase, may inhibit SOCE, the main source for eNOS activation, in vascular endothelium [97]. 


\section{References}

[1] Li L, Rose P, Moore PK. Hydrogen sulfide and cell signaling. Annu Rev Pharmacol Toxicol 2011 Feb 10;51:169-87.

[2] Wang R. Physiological implications of hydrogen sulfide: a whiff exploration that blossomed. Physiol Rev 2012 Apr;92(2):791-896.

[3] Mustafa AK, Gadalla MM, Snyder SH. Signaling by gasotransmitters. Science Signaling 2009;2(68):re2.

[4] Shibuya N, Tanaka M, Yoshida M, Ogasawara Y, Togawa T, Ishii K, et al. 3-Mercaptopyruvate sulfurtransferase produces hydrogen sulfide and bound sulfane sulfur in the brain. Antioxid Redox Signal 2009 Apr;11(4):703-14.

[5] Mustafa AK, Gadalla MM, Sen N, Kim S, Mu W, Gazi SK, et al. H2S signals through protein Ssulfhydration. Science Signaling 2009;2(96):ra72.

[6] Tan BH, Wong PT-H, Bian J-S. Hydrogen sulfide: A novel signaling molecule in the central nervous system. Neurochemistry International 2009 Aug 22.

[7] Li L, Hsu A, Moore PK. Actions and interactions of nitric oxide, carbon monoxide and hydrogen sulphide in the cardiovascular system and in inflammation--a tale of three gases! Pharmacol Ther 2009 Sep 1;123(3):386-400.

[8] Mancardi D, Penna C, Merlino A, Del Soldato P, Wink DA, Pagliaro P. Physiological and pharmacological features of the novel gasotransmitter: hydrogen sulfide. Biochim Biophys Acta 2009 Jul 1;1787(7):864-72.

[9] Furne J, Saeed A, Levitt MD. Whole tissue hydrogen sulfide concentrations are orders of magnitude lower than presently accepted values. Am J Physiol Regul Integr Comp Physiol 2008 Nov;295(5):R1479-85.

[10] Whitfield NL, Kreimier EL, Verdial FC, Skovgaard N, Olson KR. Reappraisal of H2S/sulfide concentration in vertebrate blood and its potential significance in ischemic preconditioning and vascular signaling. Am J Physiol Regul Integr Comp Physiol 2008 Jun;294(6):R1930-7.

[11] Mancardi D, Pla AF, Moccia F, Tanzi F, Munaron L. Old and New Gasotransmitters in the Cardiovascular System: Focus on the Role of Nitric Oxide and Hydrogen Sulfide in Endothelial Cells and Cardiomyocytes. Curr Pharm Biotechnol 2011 Jan 11;Jan 11. [Epub ahead of print].

[12] Tang G, Wu L, Wang R. Interaction of hydrogen sulfide with ion channels. Clin Exp Pharmacol Physiol 2010 Jul 1;37(7):753-63.

[13] Mustafa AK, Sikka G, Gazi SK, Steppan J, Jung SM, Bhunia AK, et al. Hydrogen sulfide as endothelium-derived hyperpolarizing factor sulfhydrates potassium channels. Circ Res 2011 Nov $11 ; 109(11): 1259-68$.

[14] Gadalla MM, Snyder SH. Hydrogen sulfide as a gasotransmitter. J Neurochem 2010 Apr 1;113(1):1426. 
[15] Caliendo G, Cirino G, Santagada V, Wallace JL. Synthesis and biological effects of hydrogen sulfide (H2S): development of H2S-releasing drugs as pharmaceuticals. J Med Chem 2010 Sep 9;53(17):6275-86.

[16] Skovgaard N, Gouliaev A, Aalling M, Simonsen U. The role of endogenous H2S in cardiovascular physiology. Curr Pharm Biotechnol 2011 Sep;12(9):1385-93.

[17] Wilkinson WJ, Kemp PJ. Carbon monoxide: an emerging regulator of ion channels. The Journal of Physiology 2011 Jul 01;589(Pt 13):3055-62.

[18] Peers C, Bauer CC, Boyle JP, Scragg JL, Dallas ML. Modulation of Ion Channels by Hydrogen Sulfide. Antioxid Redox Signal 2012 Jan 13.

[19] Yoshida T, Inoue R, Morii T, Takahashi N, Yamamoto S, Hara Y, et al. Nitric oxide activates TRP channels by cysteine S-nitrosylation. Nat Chem Biol 2006 Nov;2(11):596-607.

[20] Tello D, Tarín C, Ahicart P, Bretón-Romero R, Lamas S, Martínez-Ruiz A. A "fluorescence switch" technique increases the sensitivity of proteomic detection and identification of S-nitrosylated proteins. Proteomics 2009 Dec 1;9(23):5359-70.

[21] Sen N, Paul BD, Gadalla MM, Mustafa AK, Sen T, Xu R, et al. Hydrogen sulfide-linked sulfhydration of NF-kappaB mediates its antiapoptotic actions. Mol Cell 2012 Jan 13;45(1):13-24.

[22] Jiang B, Tang G, Cao K, Wu L, Wang R. Molecular mechanism for H(2)S-induced activation of K(ATP) channels. Antioxid Redox Signal 2010 May 15;12(10):1167-78.

[23] Strege PR, Bernard CE, Kraichely RE, Mazzone A, Sha L, Beyder A, et al. Hydrogen sulfide is a partially redox-independent activator of the human jejunum Na+ channel, Nav1.5. AJP: Gastrointestinal and Liver Physiology 2011 Jul;300(6):G1105-14.

[24] Andrikopoulos P, Fraser SP, Patterson L, Ahmad Z, Burcu H, Ottaviani D, et al. Angiogenic functions of voltage-gated $\mathrm{Na}+$ Channels in human endothelial cells: modulation of vascular endothelial growth factor (VEGF) signaling. Journal of Biological Chemistry 2011 Jun 13;286(19):16846-60.

[25] Catterall WA. Voltage-gated calcium channels. Cold Spring Harb Perspect Biol 2011 Aug;3(8):a003947.

[26] Bian JS, Yong QC, Pan TT, Feng ZN, Ali MY, Zhou S, et al. Role of hydrogen sulfide in the cardioprotection caused by ischemic preconditioning in the rat heart and cardiac myocytes. J Pharmacol Exp Ther 2006 Feb;316(2):670-8.

[27] Elrod JW, Calvert JW, Morrison J, Doeller JE, Kraus DW, Tao L, et al. Hydrogen sulfide attenuates myocardial ischemia-reperfusion injury by preservation of mitochondrial function. Proc Natl Acad Sci U S A 2007 Sep 25;104(39):15560-5.

[28] Lefer DJ. A new gaseous signaling molecule emerges: cardioprotective role of hydrogen sulfide. Proc Natl Acad Sci U S A 2007 Nov 13;104(46):17907-8.

[29] Ji Y, Pang QF, Xu G, Wang L, Wang JK, Zeng YM. Exogenous hydrogen sulfide postconditioning protects isolated rat hearts against ischemia-reperfusion injury. Eur J Pharmacol 2008 Jun 10;587(1-3):1-7. 
[30] Sun YG, Cao YX, Wang WW, Ma SF, Yao T, Zhu YC. Hydrogen sulphide is an inhibitor of L-type calcium channels and mechanical contraction in rat cardiomyocytes. Cardiovasc Res 2008 Sep 1;79(4):63241.

[31] Calvert JW, Jha S, Gundewar S, Elrod JW, Ramachandran A, Pattillo CB, et al. Hydrogen sulfide mediates cardioprotection through Nrf2 signaling. Circ Res 2009 Aug 14;105(4):365-74.

[32] Elsey DJ, Fowkes RC, Baxter GF. Regulation of cardiovascular cell function by hydrogen sulfide (H(2)S). Cell Biochem Funct 2010 Mar;28(2):95-106.

[33] Yong QC, Cheong JL, Hua F, Deng LW, Khoo YM, Lee HS, et al. Regulation of heart function by endogenous gaseous mediators-crosstalk between nitric oxide and hydrogen sulfide. Antioxid Redox Signal 2011 Jun;14(11):2081-91.

[34] Zhang R, Sun Y, Tsai H, Tang C, Jin H, Du J. Hydrogen Sulfide Inhibits L-Type Calcium Currents Depending upon the Protein Sulfhydryl State in Rat Cardiomyocytes. PLoS One 2012;7(5):e37073.

[35] Geng B, Yang J, Qi Y, Zhao J, Pang Y, Du J, et al. H2S generated by heart in rat and its effects on cardiac function. Biochem Biophys Res Commun 2004 Jan 9;313(2):362-8.

[36] Xu M, Wu YM, Li Q, Wang FW, He RR. Electrophysiological effects of hydrogen sulfide on guinea pig papillary muscles in vitro. Sheng Li Xue Bao 2007 Apr 25;59(2):215-20.

[37] Xu M, Wu YM, Li Q, Liu S, He RR. Electrophysiological effects of hydrogen sulfide on human atrial fibers. Chin Med J (Engl) 2011 Nov;124(21):3455-9.

[38] Lipscombe D, Helton TD, Xu W. L-type calcium channels: the low down. J Neurophysiol 2004 Nov;92(5):2633-41.

[39] Nagai $\mathrm{Y}$, Tsugane M, Oka J, Kimura H. Hydrogen sulfide induces calcium waves in astrocytes. FASEB J 2004 Mar 1;18(3):557-9.

[40] Hennig B, Diener M. Actions of hydrogen sulphide on ion transport across rat distal colon. British Journal of Pharmacology 2009 Nov;158(5):1263-75.

[41] Perez-Reyes E. Molecular physiology of low-voltage-activated t-type calcium channels. Physiol Rev 2003 Jan;83(1):117-61.

[42] Major TC, Dhamija S, Black N, Liachenko S, Morenko B, Sobocinski G, et al. The T- and L-type calcium channel blocker ( $C C B$ ) mibefradil attenuates leg edema induced by the L-type CCB nifedipine in the spontaneously hypertensive rat: a novel differentiating assay. J Pharmacol Exp Ther 2008 Jun;325(3):72331.

[43] Maeda Y, Aoki Y, Sekiguchi F, Matsunami M, Takahashi T, Nishikawa H, et al. Hyperalgesia induced by spinal and peripheral hydrogen sulfide: evidence for involvement of Cav3.2 T-type calcium channels. Pain 2009 Mar;142(1-2):127-32.

[44] Kawabata A, Ishiki T, Nagasawa K, Yoshida S, Maeda Y, Takahashi T, et al. Hydrogen sulfide as a novel nociceptive messenger. Pain 2007 Nov;132(1-2):74-81. 
[45] Okubo K, Matsumura M, Kawaishi Y, Aoki Y, Matsunami M, Okawa Y, et al. Hydrogen sulfideinduced mechanical hyperalgesia and allodynia require activation of both $\mathrm{Ca}(\mathrm{v}) 3.2$ and TRPA1 channels in mice. Br J Pharmacol 2012 Feb 2.

[46] Fukushima O, Nishimura S, Matsunami M, Aoki Y, Nishikawa H, Ishikura H, et al. Phosphorylation of ERK in the spinal dorsal horn following pancreatic pronociceptive stimuli with proteinase-activated receptor-2 agonists and hydrogen sulfide in rats: evidence for involvement of distinct mechanisms. J Neurosci Res 2010 Nov 1;88(14):3198-205.

[47] Takahashi T, Aoki Y, Okubo K, Maeda Y, Sekiguchi F, Mitani K, et al. Upregulation of Cav3.2 T-type calcium channels targeted by endogenous hydrogen sulfide contributes to maintenance of neuropathic pain. Pain 2010;150(1):183-91.

[48] Okubo K, Takahashi T, Sekiguchi F, Kanaoka D, Matsunami M, Ohkubo T, et al. Inhibition of T-type calcium channels and hydrogen sulfide-forming enzyme reverses paclitaxel-evoked neuropathic hyperalgesia in rats. Neuroscience 2011 Aug 11;188:148-56.

[49] Nagasawa K, Tarui T, Yoshida S, Sekiguchi F, Matsunami M, Ohi A, et al. Hydrogen sulfide evokes neurite outgrowth and expression of high-voltage-activated Ca2+ currents in NG108-15 cells: involvement of T-type Ca2+ channels. J Neurochem 2009 Feb;108(3):676-84.

[50] Joksovic PM, Nelson MT, Jevtovic-Todorovic V, Patel MK, Perez-Reyes E, Campbell KP, et al. CaV3.2 is the major molecular substrate for redox regulation of T-type $\mathrm{Ca} 2+$ channels in the rat and mouse thalamus. J Physiol 2006 Jul 15;574(Pt 2):415-30.

[51] Yong QC, Choo CH, Tan BH, Low C-M, Bian J-S. Effect of hydrogen sulfide on intracellular calcium homeostasis in neuronal cells. Neurochemistry International 2010 Feb 1;56(3):508-15.

[52] Lee SW, Hu YS, Hu LF, Lu Q, Dawe GS, Moore PK, et al. Hydrogen sulphide regulates calcium homeostasis in microglial cells. Glia 2006 Aug 1;54(2):116-24.

[53] Venkatachalam K, Montell C. TRP channels. Annu Rev Biochem 2007;76:387-417.

[54] Gees M, Colsoul B, Nilius B. The role of transient receptor potential cation channels in Ca2+ signaling. Cold Spring Harb Perspect Biol 2010 Oct;2(10):a003962.

[55] Wang L, Cvetkov TL, Chance MR, Moiseenkova-Bell VY. Identification of in vivo disulfide conformation of the TRPA1 ion channel. J Biol Chem 2011 Dec 29.

[56] Bhatia M, Wong FL, Fu D, Lau HY, Moochhala SM, Moore PK. Role of hydrogen sulfide in acute pancreatitis and associated lung injury. Faseb J 2005 Apr;19(6):623-5.

[57] Trevisani M, Patacchini R, Nicoletti P, Gatti R, Gazzieri D, Lissi N, et al. Hydrogen sulfide causes vanilloid receptor 1-mediated neurogenic inflammation in the airways. British journal of pharmacology 2005 Aug 1;145(8):1123-31.

[58] Schicho R, Krueger D, Zeller F, von Weyhern CWH, Frieling T, Kimura H, et al. Hydrogen sulfide is a novel prosecretory neuromodulator in the Guinea-pig and human colon. Gastroenterology 2006 Nov;131(5):1542-52. 
[59] Hutter MM, Wick EC, Day AL, Maa J, Zerega EC, Richmond AC, et al. Transient receptor potential vanilloid (TRPV-1) promotes neurogenic inflammation in the pancreas via activation of the neurokinin-1 receptor (NK-1R). Pancreas 2005 Apr;30(3):260-5.

[60] Patacchini R, Santicioli P, Giuliani S, Maggi CA. Hydrogen sulfide (H2S) stimulates capsaicin-sensitive primary afferent neurons in the rat urinary bladder. British Journal of Pharmacology 2004 Jun;142(1):31-4.

[61] Patacchini R, Santicioli P, Giuliani S, Maggi CA. Pharmacological investigation of hydrogen sulfide (H2S) contractile activity in rat detrusor muscle. European Journal of Pharmacology 2005 Mar 21;509(23):171-7.

[62] Tang HB, Li YS, Miyano K, Nakata Y. Phosphorylation of TRPV1 by neurokinin-1 receptor agonist exaggerates the capsaicin-mediated substance $\mathrm{P}$ release from cultured rat dorsal root ganglion neurons. Neuropharmacology 2008 Dec;55(8):1405-11.

[63] Tang HB, Nakata Y. The activation of transient receptor potential vanilloid receptor subtype 1 by capsaicin without extracellular $\mathrm{Ca} 2+$ is involved in the mechanism of distinct substance $\mathrm{P}$ release in cultured rat dorsal root ganglion neurons. Naunyn Schmiedebergs Arch Pharmacol 2008 Jun;377(4-6):325-32.

[64] Ang SF, Moochhala SM, MacAry PA, Bhatia M. Hydrogen sulfide and neurogenic inflammation in polymicrobial sepsis: involvement of substance $P$ and ERK-NF-kappaB signaling. PLoS One 2011;6(9):e24535.

[65] Ang SF, Sio SW, Moochhala SM, MacAry PA, Bhatia M. Hydrogen sulfide upregulates cyclooxygenase-2 and prostaglandin E metabolite in sepsis-evoked acute lung injury via transient receptor potential vanilloid type 1 channel activation. J Immunol 2011 Nov 1;187(9):4778-87.

[66] Medeiros JV, Bezerra VH, Gomes AS, Barbosa AL, Lima-Junior RC, Soares PM, et al. Hydrogen sulfide prevents ethanol-induced gastric damage in mice: role of ATP-sensitive potassium channels and capsaicinsensitive primary afferent neurons. J Pharmacol Exp Ther 2009 Sep;330(3):764-70.

[67] Cvetkov TL, Huynh KW, Cohen MR, Moiseenkova-Bell VY. Molecular architecture and subunit organization of TRPA1 channel revealed by electron microscopy. Journal of Biological Chemistry 2011 Sep 09.

[68] Lapointe TK, Altier C. The role of TRPA1 in visceral inflammation and pain. Channels (Austin) 2011 Nov $1 ; 5(6)$.

[69] Moran MM, McAlexander MA, Bíró T, Szallasi A. Transient receptor potential channels as therapeutic targets. Nature Reviews Drug Discovery 2011;10(8):601-20.

[70] Streng T, Axelsson HE, Hedlund P, Andersson DA, Jordt S-E, Bevan S, et al. Distribution and function of the hydrogen sulfide-sensitive TRPA1 ion channel in rat urinary bladder. Eur Urol 2008 Feb 1;53(2):391-9.

[71] Everaerts W, Vriens J, Owsianik G, Appendino G, Voets T, de Ridder D, et al. Functional characterization of transient receptor potential channels in mouse urothelial cells. AJP: Renal Physiology 2010 Apr;298(3):F692-701. 
[72] Gratzke C, Streng T, Waldkirch E, Sigl K, Stief C, Andersson KE, et al. Transient receptor potential A1 (TRPA1) activity in the human urethra--evidence for a functional role for TRPA1 in the outflow region. Eur Urol 2009 Mar;55(3):696-704.

[73] Miyamoto R, Otsuguro K, Ito S. Time- and concentration-dependent activation of TRPA1 by hydrogen sulfide in rat DRG neurons. Neurosci Lett 2011 Jul 20;499(2):137-42.

[74] Dong Y, Shi HL, Shi JR, Wu DZ. Transient receptor potential A1 is involved in cold-induced contraction in the isolated rat colon smooth muscle. Sheng Li Xue Bao 2010 Aug 25;62(4):349-56.

[75] Papapetropoulos A, Pyriochou A, Altaany Z, Yang G, Marazioti A, Zhou Z, et al. Hydrogen sulfide is an endogenous stimulator of angiogenesis. Proc Natl Acad Sci USA 2009 Dec 2.

[76] Wang MJ, Cai WJ, Li N, Ding YJ, Chen Y, Zhu YC. The hydrogen sulfide donor NaHS promotes angiogenesis in a rat model of hind limb ischemia. Antioxid Redox Signal 2010 May 1;12(9):1065-77.

[77] Wang MJ, Cai WJ, Zhu YC. The Mechanisms of Angiogenesis: A Role of Hydrogen Sulphide. Clin Exp Pharmacol Physiol 2010 Feb 10;37(7):764-71.

[78] Coletta C, Papapetropoulos A, Erdelyi K, Olah G, Modis K, Panopoulos P, et al. Hydrogen sulfide and nitric oxide are mutually dependent in the regulation of angiogenesis and endothelium-dependent vasorelaxation. Proc Natl Acad Sci U S A 2012 May 8.

[79] Pupo E, Fiorio Pla A, Avanzato D, Moccia F, Avelino-Cruz JE, Tanzi F, et al. Hydrogen sulfide promotes calcium signals and migration in tumor-derived endothelial cells. Free radical biology \&amp; medicine 2011 Nov 01;51(9):1765-73.

[80] Cheng HW, James AF, Foster RR, Hancox JC, Bates DO. VEGF activates receptor-operated cation channels in human microvascular endothelial cells. Arteriosclerosis, Thrombosis, and Vascular Biology 2006 Aug 1;26(8):1768-76.

[81] Pocock TM, Foster RR, Bates DO. Evidence of a role for TRPC channels in VEGF-mediated increased vascular permeability in vivo. Am J Physiol Heart Circ Physiol 2004 Mar 1;286(3):H1015-26.

[82] Hamdollah Zadeh MA, Glass CA, Magnussen A, Hancox JC, Bates DO. VEGF-mediated elevated intracellular calcium and angiogenesis in human microvascular endothelial cells in vitro are inhibited by dominant negative TRPC6. Microcirculation (New York, NY : 1994) 2008 Oct 1;15(7):605-14.

[83] Mehta D, Ahmmed GU, Paria BC, Holinstat M, Voyno-Yasenetskaya T, Tiruppathi C, et al. RhoA interaction with inositol 1,4,5-trisphosphate receptor and transient receptor potential channel-1 regulates Ca2+ entry. Role in signaling increased endothelial permeability. J Biol Chem 2003 Aug 29;278(35):33492500.

[84] Paria BC, Vogel SM, Ahmmed GU, Alamgir S, Shroff J, Malik AB, et al. Tumor necrosis factor-alphainduced TRPC1 expression amplifies store-operated $\mathrm{Ca} 2+$ influx and endothelial permeability. Am J Physiol Lung Cell Mol Physiol 2004 Dec 1;287(6):L1303-13.

[85] Jho D, Mehta D, Ahmmed G, Gao XP, Tiruppathi C, Broman M, et al. Angiopoietin-1 opposes VEGFinduced increase in endothelial permeability by inhibiting TRPC1-dependent Ca2 influx. Circ Res 2005 Jun 24;96(12):1282-90. 
[86] Yu PC, Gu SY, Bu JW, Du JL. TRPC1 is essential for in vivo angiogenesis in zebrafish. Circ Res 2010 Apr 16;106(7):1221-32.

[87] Abdullaev IF, Bisaillon JM, Potier M, Gonzalez JC, Motiani RK, Trebak M. Stim1 and Orai1 mediate CRAC currents and store-operated calcium entry important for endothelial cell proliferation. Circ Res 2008 Nov 21;103(11):1289-99.

[88] Li J, Cubbon RM, Wilson LA, Amer MS, McKeown L, Hou B, et al. Orai1 and CRAC channel dependence of VEGF-activated Ca2+ entry and endothelial tube formation. Circ Res 2011 May 13;108(10):1190-8.

[89] Cahalan MD. STIMulating store-operated Ca(2+) entry. Nat Cell Biol 2009 Jun;11(6):669-77.

[90] Antigny F, Girardin N, Frieden M. Transient receptor potential canonical channels are required for in vitro endothelial tube formation. J Biol Chem 2012 Feb 17;287(8):5917-27.

[91] Fiorio Pla A, Avanzato D, Munaron L, Ambudkar IS. Ion channels and transporters in cancer. 6. Vascularizing the tumor: TRP channels as molecular targets. Am J Physiol Cell Physiol 2012 Jan;302(1):C915.

[92] Fiorio Pla A, Ong HL, Cheng KT, Brossa A, Bussolati B, Lockwich T, et al. TRPV4 mediates tumorderived endothelial cell migration via arachidonic acid-activated actin remodeling. Oncogene 2012 Jan 12;31(2):200-12.

[93] Shen X, Peter EA, Bir S, Wang R, Kevil CG. Analytical measurement of discrete hydrogen sulfide pools in biological specimens. Free Radic Biol Med 2012 Apr 19.

[94] Moccia F, Bertoni G, Pla AF, Dragoni S, Pupo E, Merlino A, et al. Hydrogen Sulfide Regulates Intracellular $\mathrm{Ca}((2+))$ Concentration in Endothelial Cells From Excised Rat Aorta. Current pharmaceutical biotechnology 2011 Apr 20.

[95] Bauer CC, Boyle JP, Porter KE, Peers C. Modulation of $\mathrm{Ca}(2+)$ signalling in human vascular endothelial cells by hydrogen sulfide. Atherosclerosis $2010 \mathrm{Apr} ; 209(2): 374-80$.

[96] Yang G, Wu L, Jiang B, Yang W, Qi J, Cao K, et al. H2S as a physiologic vasorelaxant: hypertension in mice with deletion of cystathionine gamma-lyase. Science (New York, NY) 2008 Oct 24;322(5901):587-90.

[97] Dedkova EN, Blatter LA. Nitric oxide inhibits capacitative Ca2+ entry and enhances endoplasmic reticulum Ca2+ uptake in bovine vascular endothelial cells. J Physiol (Lond) 2002 Feb 15;539(Pt 1):77-91. 


\section{FIGURE LEGENDS}

Figure 1. Modulation of plasmalemmal $\mathrm{Ca}^{2+}$ channels by hydrogen sulfide. Hydrogen sulfide $\left(\mathrm{H}_{2} \mathrm{~S}\right)$ regulates the gating of a number of $\mathrm{Ca}^{2+}$-permeable channels, including 1) L-type VOCs formed by either Cav1.2 or Cav1.3 subunits, 2) T-type VOCs composed by Cav2.3 subunits; 3) Transient Receptor Potential Ankyrin 1 (TRPA1); and 4) Transient Receptor Potential Vanilloid 1 (TRPV1). As more extensively described in the test, $\mathrm{H}_{2} \mathrm{~S}$ inhibits L-type VOCs in cardiac myocytes, whereas it activates them in neurons. Similarly, $\mathrm{H}_{2} \mathrm{~S}$ stimulates T-type VOCs, TRPAl and TRPV1 both in vitro and in vivo. The identity of putative proangiogenic calcium-permeable channels (TRPs?), possibly modulated by H2S, is unknown.

Table 1. Tissue distribution and functional roles of the $\mathrm{Ca}^{2+}$-permeable channels sensitive to hydrogen sulfide. 